Journal of Critical Race Inquiry

Volume 7, Number 1 (2020) pp. 76-83

\title{
The Reimagining Kinship, Gender, and Sexuality in Indigenous Communities Colloquium: An Overview and Reflective Essay
}

\author{
Natasha Stirrett \\ Cultural Studies, Queen's University
}

The Reimagining Kinship, Gender, and Sexuality in Indigenous Communities Colloquium was held in Kingston, Ontario at Queen's University in January 2019. Generously hosted by the Journal of Critical Race Inquiry (JCRI) and the Department of Gender Studies, Sexual and Gender Diversity Certificate Program, this day-long event brought together clan mothers, Indigenous scholars, community members, and graduate students. The audience was a mix of Queen's students, faculty, and the wider local Indigenous and non-Indigenous community. The overarching aim of the day was to provide a space for meaningful dialogue on gender, sexuality, cultural revitalization and relations within Indigenous communities. This special section of this Journal of Critical Race Inquiry (JCRI) issue highlights some of the Indigenous intellectual work emerging from the Colloquium. The written pieces presented here cover some of the themes related to love, two-spirit identities, governance, kinship, consent, storytelling, and belonging. It is our hope the Reimagining Kinship, Gender and Sexuality in Indigenous Communities Colloquium and this special report from JCRI will spark further conversations and ideas that will contribute to the cultural resurgence of our Indigenous communities and knowledges across Turtle Island and among all our relations - human and more-than-human.

The Colloquium opened with an acknowledgement of the shared traditional territories of the Anishinaabe and Haudenosaunee upon which the Colloquium was being held. The land acknowledgement encouraged reflection by those in attendance to think about the larger histories and relationships that predated the institutional space of the university. 
Kanonhsyonne (Janice) Hill, in her role as a Clan Mother and Associate Vice Principal in the Office of Indigenous Initiatives and Reconciliation, gave the Ohen:ton Karihwatehkwen address to offer a thank you to the creator and creation. For those unfamiliar, the thanksgiving address is spoken to bring our minds together as one and to facilitate our connection to the land and all our relations. As Kanonhsyonne Hill spoke, Dana Wesley, acting as a helper, walked through the space offering smudging to participants of the Colloquium. With the tone set for the day, the energy in the room was placid, yet lively. Folks were quietly beading at the beading station while those seated in the audience also patiently waited for the Colloquium presentations to begin.

Our keynote speaker for the day was Dr. Kim TallBear, who is a citizen of the Sisseton-Wahpeton Oyate and an Associate Professor in the Faculty of Native Studies at the University of Alberta and a Canadian Research Chair in Indigenous peoples, Technoscience \& Environment. Dr. TallBear's talk, "Decolonial Love and Sustainable Relations," offered valuable critique on the colonization of Indigenous sexuality and insights into new and old ways of relating to each other and our more-than-human relatives. For TallBear, in this current age of the nation state neoliberalism and global environmental degradation we need to consider new ways of being in the world, which includes interrogating colonial and unsustainable relations such as "monogamous, heteronormative, and marriagefocused nuclear family ideals." As TallBear argues, our Indigenous expansive but not limitless

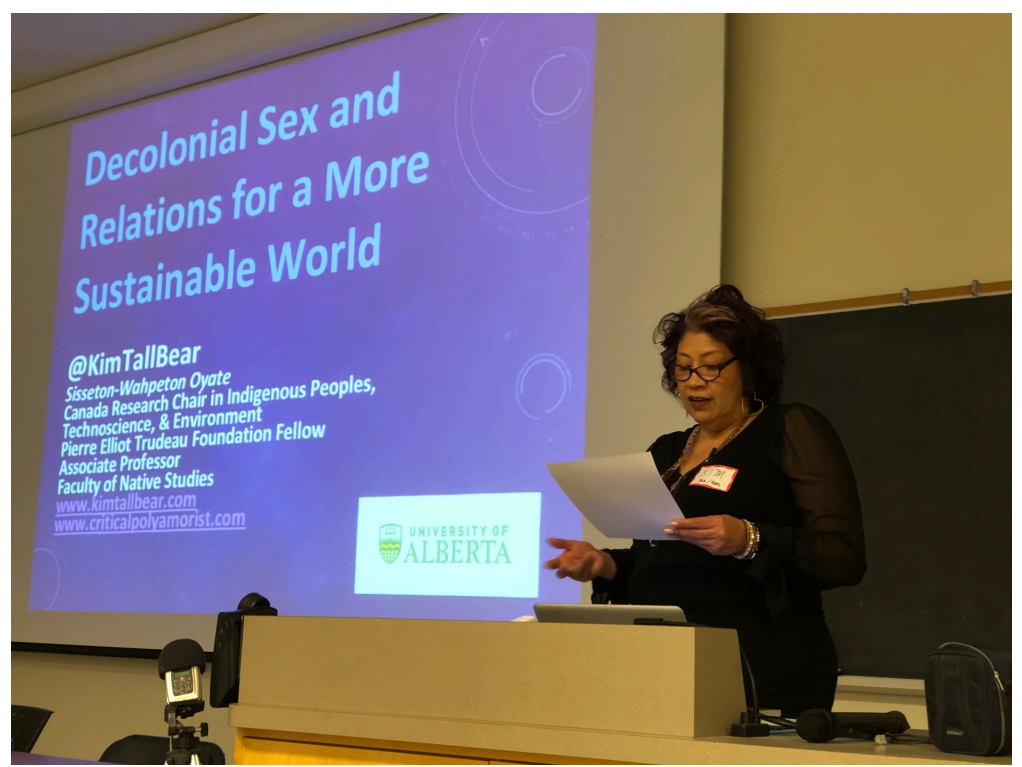

Figure 1: Dr. Kim TallBear during her keynote. (Photo credit: Laura Pascoe) understandings of kin, including our more-than-human kin, can rouse us into more sustainable and just relations.

Joshua Whitehead, an Ojibwe-nehiyaw, member of Peguis First Nation (Treaty 1), two-spirit and a well-respected poet and scholar, offered insightful and thoughtful considerations in response to Kim TallBear's talk in thinking about two-spiritedness, sexuality, kinship, language, and Cree expansive understandings of the family. He offered examples of calling his niece in English "his baby" and referenced his cousins as siblings, 
gesturing to the wider web of kinship existing in his Cree community beyond the narrow, Western conceptions of the nuclear family. Whitehead discussed how coming out/in as a queer two-spirit person was met with a sense of a community contemplation of the future.

For Whitehead, it seemed from this perspective as though his being gay or two-spirit disrupted the futurity of indigenity. After reflecting on TallBear's keynote, he posed the question to himself on whether two-spiritedness is about relations and kinship in its entirety. He said, "in calling my niece 'my baby,' do I not contribute to relation with the community and our relation to their future?" Later, in Whitehead's response, he considered whether the addition of $2 \mathrm{~S}$ in $\mathrm{LGBTQ}^{+}$signifiers is relevant because two-spiritedness is a sovereign signifier in its own right that encompasses a very particular epistemology and worldview tied to the people and land from where it comes from. Joshua Whitehead then presented a talk entitled "Owning a Body That Wants to Break: Queer Indigenous Body Dysmorphia" during the Colloquium. Overall, as indicated by Kim TallBear and Joshua Whitehead, their panel presentations attended to thinking in and around options and possibilities for gender expression, sexuality, and relating previously foreclosed to us as Indigenous peoples because of colonialism and State discipline.

During the discussion period following TallBear and Whitehead's presentations, the

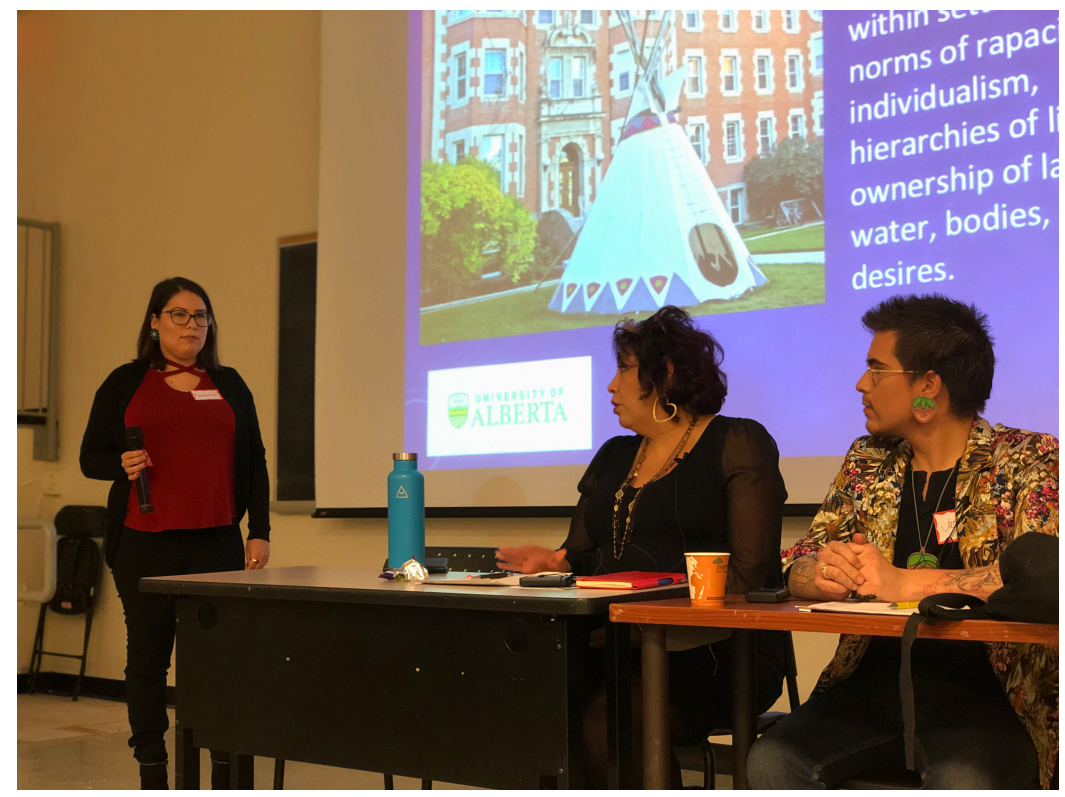

Figure 2: Natasha Stirrett facilitating the discussion period with Dr. TallBear and Joshua Whitehead (Photo credit: Laura Pascoe) audience raised questions to further delve into considerations on difficult conversations relating to spirituality and reimagining kinship, gender, and sexuality within our communities. The challenges existing in many Indigenous communities as a result of residential schools, internalized trauma, sexism, and shame around gender and sexuality were mentioned. For example, TallBear spoke to asexual polyamory practices where, for some, decentering the topic of sex in their relations is an ideal. Whitehead spoke of having conversations at the dinner table with his dad on queerness and snagging and also how, through our relations and engagement, we can reembrace our traditions and appreciation for gender and sexual diversity. He also discussed the 
importance of understanding that, in particular contexts, young Indigenous men are only just beginning to think about and learn to be good partners and parents, thus might not have the tools and capacity to take up the emotional complexities and ethics of polygamous relationships. In conversation with the audience, TallBear acknowledged class dynamics and privilege in taking on this topic in the way she does because of her positionality and the privilege inherent in engaging in certain types of relationships. In recognizing the challenges of decolonizing our relationships and communities as articulated by TallBear, we also see the need to continue to build spaces where, 20 years down the road, there will be more choices and options opened up for people in terms of ways of relating and being. Through this conversation the audience could see that, in re-imagining kinship, gender, and sexuality in the aftermath of colonization and colonial histories, there are no limits to re-claiming and creating our collective future of multitudes.

The next panel, "A Conversation with Clan Mothers, Kanonhsyonne \& Iehnhotonkwas: I Don't Think the Creator Really Cares About Gender," was chaired by Queen's Assistant Professor in Gender Studies Dr. Scott Morgensen and, as the title suggests, featured two clan mothers, Kanonhsyonne and Iehnhotonkwas from Tyendinaga Mohawk Territory. Scott Morgensen introduced Kanonhsyonne Janice Hill as Turtle Clan, a clan mother, Mohawk, mother, and an Associate Vice-Principal in the Office of Indigenous Initiatives and Reconciliation at Queen's University. Kanonhsyonne has spent her life working for the revitalization of the Mohawk language and the knowledge, culture, and spirituality of her ancestors and in furthering Indigenous education and creating positive learning experiences for

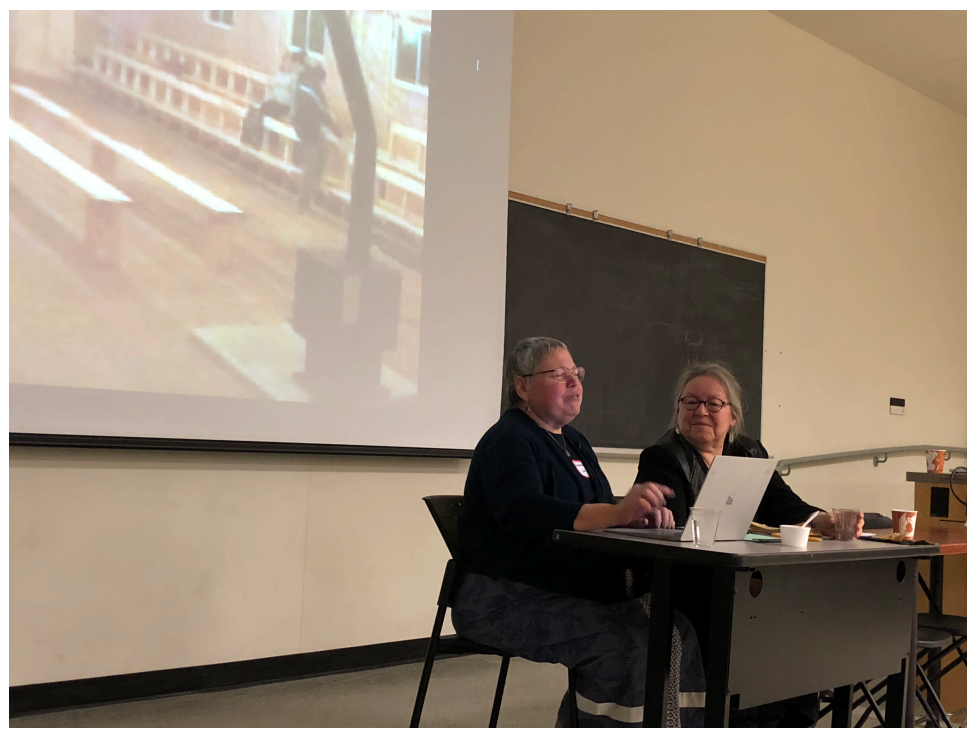

Figure 3: Clan mothers Kanonhsyonne Janice Hill and Iehnhototonkwa Bonnie Jane Maracle speak during their panel. (Photo credit: Laura Pascoe)

Indigenous students. Kanonhsyonne is also currently completing her Master of Arts in Gender Studies at Queen's University. As introduced by Scott Morgensen, Iehnhotonkwas Bonnie Jane Maracle, the second clan mother, identifies as Wolf Clan, Mohawk, and a clan mother 
who holds a BA in Indigenous Studies from Trent University, a B.Ed. from Queen's University and is a $\mathrm{PhD}$ Candidate in Indigenous Studies at Trent University.

Kanonhsyonne's research explores gender identity, roles and responsibilities in the longhouse based on her traditional knowledge, engagement with her longhouse community, and in-person interviews. This panel discussed the considerations explored in "determining inclusion, responsibilities, and recognition within the longhouse community." In situating the broader conversation of gender identity, roles and responsibilities in the longhouse, Iehnhotonkwas Bonnie Jane Maracle began the panel discussion by illuminating the essence of what it means to be Haudenosaunee, to be Mohawk, and to have the worldview and ethics encompassing this way of life. She emphasized the value in mindfulness, respect for creation, and work related to the integrity and cohesiveness of the community. As a communal society, Iehnhotonkwas affirms there is a simplicity in the measure of being in good relation and is gauged by how you conduct yourself, act towards others, and the contributions made to maintain a healthy and whole community. Iehnhotonkwas points out how maintaining Haudenosaunee way of life is challenging amid the pervasive effects of colonialism on their people and culture. As expressed by Iehnhotonkwas, residential schools created a devastating separation of self and spirit. The experiences of residential schools disrupted the relational knowledge of nurturing relationships that had been passed down in the community from generation to generation. However, as Iehnhotonkwas observes in Tyendinaga and as evidenced in their clan structure, the concepts and foundation of who Haudenosaunee people are and how they move in the world endures. In our contemporary moment, for Iehnhotonkwas, cultural continuity is important and she encourages seeing people for their gifts in avoidance of internalizing Western-imposed labels or hierarchal classifications that generate discrimination.

Specifically, Iehnhotonkwas contended that the Western societal classification of gender is a process of Othering and a part of colonialism. For Iehnhotonkwas, because of settler colonialism, there was an encroachment into Haudenosaunee way of life that resulted in the substantial loss of valued aspects of their culture. To address this harm, she argues that Haudenosaunee people need to reclaim who they are. Within the community, Iehnhotonkwas said she could not recall from oral history members being restricted to contribute in ways that did not suit them based on constructions of gender or their sexuality. For example, while gendered roles for men and women did exist, she spoke of the historical practice of people within the community self-determining the roles they took up, such as cooking or being a warrior. She spoke of a sense of gender fluidity, normativity, and acceptance that existed. Traditionally, there was greater focus on whether members were contributing - according to 
their ability and capacity - as later indicated by Kanonhsyonne and being a good community person. Iehnhotonkwas further drew attention to the ways in which human beings are measured through how they act in relation to all the rest of creation. In her closing words, Iehnhotonkwas poses, "As long as you are doing things in a good way, we are being lifted by all of the other entities in creation. All their strength lifts us up and helps us as well. This relationship is being maintained in our ceremonies."

Following Iehnhotonkwas's clan mother teaching, Kanonhsyonne brought the conversation back to the title of the panel, "I Don't Think the Creator Really Cares About Gender," conveying that these words were shared from one of the narrators Kanonhsyonne interviewed. Kanonhsyonne pointedly articulated that, historically and socially, many of her people would agree gender identity was not a concern for the creator and, in other words, gender diversity was not considered taboo. As discussed in her presentation, Kanonhsyonne's research project was inspired when she was introduced to queer theory during her first year in the Gender Studies Master's Program at Queen’s University. Later, during harvest ceremonies in the longhouse, Kanonhsyonne began to take note of who was present and absent from the space. This became the catalyst for her thinking in relation to the longhouse and gender identity. The experience raised new questions for Kanonhsyonne. How would the longhouse community react to a transperson? Would they be as unconditionally accepting as their ancestors were? This thought process set in motion Kanonhsyonne's research journey.

During the panel conversation Kanonhsyonne affirmed the longhouse as a tradition with lengthy ties to their culture and cosmology. As indicated by Kanonhsyonne, the longhouse is informed by the great law of peace, in addition to creation stories passed down through the centuries and in some communities, Gaiwiio (the code of handsome lake). Kanonhsyonne echoed Iehnhotonkwas's words of acknowledging the influence and impact of colonization on their community. For instance, she discussed how longhouses at a particular juncture in time were designed as living quarters but, later influenced by Quaker meeting houses, became a space for community meetings and ceremonial practices. Kanonhsyonne described the longhouse structure as once being divided by clan and as a gendered space, divided by the binary of men and women. However, through her research, she found that, traditionally, Haudenosaunee actually focused more on the particular gifts people carry rather than dividing people based on constructions of gender. Out of this research, Kanonhsyonne's hope is to plant seeds for future exploration and consideration. As a clan mother for the turtle clan, Kanonhsyonne's research on gender identity in the longhouse can arguably be considered as an extension of her life's commitment in cultural resurgence and building 
relationships. This endeavor will surely continue to advance and benefit her people for generations to follow.

The remaining panel presentations of the day centred on the knowledges of emerging Indigenous scholars in the fields of gender and sexuality. Dana Wesley and Geraldine King's presentations brought humour and life to the room as they engaged their audience in knowledge grounded in the Indigenous oral tradition of storytelling to convey intimate knowledges of their family, Anishinaabe erotics, and two-spirit relations. For example, Geraldine King read excerpts of Indigenous erotica speaking to love, kinship, and intimacy outside the heteronormative narrative. Her creative storytelling was compelling, provocative, and freshly appreciated by her audience because it's a reminder to both Indigenous and nonIndigenous people that we are vibrant, complex human beings capable of laughter and love and are more than just legacies of wounds and pain. Joshua Whitehead's poetic intelligence on queer Indigenity was thought-provoking. The presentation on the Indigenous Mentorship Network by Andrea Ianni \& Kasha Janota-Bzowska drew attention to the importance of mentorship and culturally appropriate learning spaces for emergent Indigenous academic leaders. Evelyn Poitras' presentation reflected on seasons, nehiyaw iskwew teachings, navigating the effects of residential schooling, and the meaning of Miyo pimatisiwin (a good life). Poitras eloquently weaved together intergenerational storying and pondered the limits of the English language and whether the concept of feminism captures the essence of what it means to be nehiyawak iskwewak, a Cree woman.

Sebastian De Line's paper "Relational Plasticity: How Clay Bundles Polyspirit," also published in this issue, offers the concept of many-spirit to a discussion of Indigenous, and transnational stories of clay to think about embodiment, discourses, and relationality illuminating the brilliancy of Indigenous epistemology. De Line's intention in thinking through his conception of "polyspirited" (many-spirited) is to offer a "space for those whose stories tell them that they are and belong to something far greater than what can be comprehended within the logic of a binary." For De Line, the possibilities opened up by clay stories produce knowledge that reveal the limits of scientific discourses to understand relations within our human and more-than-human world. Adria Kurchina-Tyson's paper, "Decolonizing Kink: Resurgence of Consent-Based Governance" and also included in this issue, advances thinking on multifaceted relating and the complex orientation of Nishinaabeg epistemologies and stories that refuses essentialist readings and interpretations. KurchinaTyson explores Anishinaabek traditionalisms to reveal how Nishinaabeg consent is not based on moral policing, but rather fosters reflexive thinking and imaginative processes. 
Taken as a whole, these conversations invite further engagement and dialogue on the re-imagining of gender, sexuality, and kinship within Indigenous communities and, rising out of these conversation threads, a multitude of loving, relating, and being that subsists, albeit colonial histories and heteropatriarchal oppression and erasure. While the depth of the loss experienced by Indigenous communities and peoples through the repression of gender, sexuality, Indigenous languages, knowledges, and cultural practices is undeniable, from the conversations and knowledge sharing that occurred during the Colloquium, it is evident we endure. Our ways of being in good relation persist, and the foundations and keys to reclaiming, envisioning, and building our communities is ours to wield. 